\title{
Abordagens Teóricas para Estudo da Teatralidade em Performances Midiáticas:
}

\author{
Dramas, roteiros, ações
}

\section{Theoretical Approaches to Study Theatricality in Media}

\section{Performances:}

\section{Dramas, scripts, actions}

Thiago Soares

Professor e pesquisador do Departamento de Comunicação da UFPE. Doutor em Comunicação e Cultura Contemporâneas pela UFBA, com pós-doutorado pela UFF. Universidade Federal de Pernambuco, Programa de Pós-Graduação em Comunicação, Recife (PE), Brasil.

Este artigo propõe pensar o conceito de performance no contexto midiático contemporâneo, uma vez que é necessário enfrentar os problemas da visibilidade numa época em que, diante dos constantes acionamentos do corpo, via fotografias, selfies, aparições em sites de redes sociais, emergem valores nas experiências que sintetizam formas de habitar um mundo codificado. Performances midiáticas são acionamentos corporais de sujeitos em ambientes de mídia envolvendo a formação de uma "vida cênica" em contextos de alta visibilidade e a construção de redes de sentido do biográfico, ou seja, o vivido e o relatado, em dinâmicas cotidianas. Performances midiáticas, na medida em que se projetam para o Outro, formam espaços especulativos de exibição, articulando prazer e convivência, mas também vigilância, controle e punição. Pressupõem valores ligados ao narcisismo e ao individualismo, mas também à 
conjunção e à aproximação, promovendo atravessamentos de mídias e enlaces entre a vida comum, as indústrias da cultura e do entretenimento e conglomerados transnacionais de mídias.

Entende-se, portanto, Performance em duas acepções: trata-se de um objeto sobre o qual se especulam e se instauram problemas de pesquisa no campo da Comunicação, mas também como um conjunto de saberes interdisciplinares que atravessam áreas do conhecimento como a Antropologia, a Sociologia, a Psicologia, as Artes Cênicas, entre outras, e ao qual se filiam ${ }^{1}$. A noção de Performance já conta com um largo conjunto de reflexões no campo da Comunicação no Brasil. Dos estudos em torno da espetacularização do eu (SIBILIA, 2008), passando por um debate mais circunscrito às redes sociais digitais a partir de valores da modernidade como coerência e racionalidade (SÁ e POLIVANOV, 2012), tangenciando as performances de gosto em redes sociais (AMARAL, 2014) e as formas de encenação dos afetos por fãs (AMARAL e MONTEIRO, 2013 e SÁ, 2016), para citar apenas alguns dos importantes trabalhos, parece-nos relevante fazer novos movimentos teóricos na tentativa de promover reordenamentos conceituais e avanços metodológicos. Uma das principais ferramentas de problematização de conceitos vigentes num campo diz respeito ao debate e à incorporação de vocabulário conceitual que acione o debate de inclinações a partir de novos objetos e questões.

Tomando como pressuposto o fato de que o conceito de Performance, já largamente utilizado na Comunicação, deriva, muito centralmente, dos estudos da Psicologia, cabe destacar a bibliografia que já vem pensando sobre a dimensão do "eu" e do "Outro" em ambientes midiáticos. Em texto datado de 1934, Mind, Self and Society, George Mead (1934) debate o espaço de criação entre o "eu" e o "Outro" a partir da regulação do que chama "instituições sociais" e postula que o que entendemos como "eu" seria, na verdade, uma resposta que sujeitos dão à vida em sociedade a partir de critérios consensuais de avaliação e expressividade. O autor parece sugerir que é no paradoxo entre o "eu" e o "Outro" que é construído um espaço de escolhas, encenações e expressividades que negociam com padrões amplamente "aceitos" e consagrados e que serão, portanto, recolocados em um contexto novo. Embora sem tratar especificamente sobre as disposições midiáticas nos sistemas de representação, é possível apreender que o autor se refere à mídia ao tratar sobre as mediações entre sujeitos e instituições sociais.

\footnotetext{
1 Para melhor esclarecimento sobre os diferentes usos das noções de performance, grafaremos "Performance", em maiúscula, quando se tratar do campo de conhecimento; e "performance", em minúscula, quando se tratar de objetos observáveis.
} 
Goffman (1969) avança em direção à pontuação em torno dos papéis, representações e disposições do "eu" na vida cotidiana, recorrendo a metáforas teatrais para incorporação de um vocabulário mais cênicos nos estudos de Performance na Comunicação. Para o autor, o indivíduo apresentar-se-ia a partir do exercício de papéis em situações do cotidiano, assumindo uma postura de constante negociação com diferentes ambientes e lógicas de encenação envolvidas. Numa síntese, Mead parece estar referindo-se a espaços, ambiências e movimentos de criação em torno de dinâmicas consensuais, enquanto Goffman se atém a práticas performáticas em si, aos papéis desempenhados e à sua inserção na construção de valores e estigmas em torno dos sujeitos. Os dois autores são fundamentais para entender ideias sobre controle, gestão da imagem, dimensões estruturantes das performances - como pode ser visto nos trabalhos subsequentes de Sibilia (2010 e 2015) e Bruno (2008) - e todo o lastro do que se configura numa crítica ao controle sobre as ações dos sujeitos, ao empreendedorismo da vida privada, aos modelos disciplinares de encenação de si e à espetacularização do eu no cotidiano.

Sustentando essa hipótese e tentando abrir frentes para a discussão em torno das formas expressivas da dimensão performática e de suas experiências no cotidiano, aposta-se numa aproximação com a tradição dos estudos de teatro, num movimento de retomar as bases teóricas a partir das quais se ergueu o debate sobre Performance, para problematizar seus usos. É do conceito fundante da natureza cênica dos fenômenos sociais que emerge a ideia de teatralidade, princípio que nasce junto com a noção de literaridade (no campo da literatura), com a função de definir a particularidade ou especificidade do teatro em diferenciação a outras artes do espetáculo. (FÉRAL, 2015, p. 81) Para além dos usos nas teorias do teatro, o conceito de teatralidade se espraia na tentativa de encontrar parâmetros comuns nos contextos de encenação, seja a partir de práticas individuais, coletivas, nas teorias de atuação ou estéticas.

Desde a passagem do século XIX para o século XX, a teatralidade questiona os limites do palco e da cena, ampliando a natureza cênica dos fenômenos para o cotidiano, promovendo aquilo que Josétte Féral chama de "condição de emergência do teatral" (p. 82), ou seja, as noções de moldura e enquadramento cênicos de fenômenos das mais diversas naturezas. A autora retoma o questionamento feito por Bernard Dort em seu ensaio A condição sociológica da mise-en-scène teatral - escrito em 1971 e traduzido no Brasil em $O$ teatro e sua realidade, seis anos depois -, a partir da premissa de que o "teatral" não resulta apenas das mudanças de um campo artístico, mas é antes resultado de mudanças que afetam o tecido social. Ou seja, o estatuto teatral dos fenômenos sociais passa a ser apreendido pelas lentes e pelas terminologias 
oriundas do campo teatral, legando, para a área das Ciências Sociais Aplicadas, uma ampliação vocabular que vai permear os estudos nas áreas de Antropologia (a partir da ideia de drama social, largamente utilizada por Victor Turner), da Psicologia Social (da qual partem os principais estudos de Goffman sobre "a invenção do eu na vida cotidiana") e dos estudos urbanos com interseç̧ões comunicacionais a partir dos inúmeros usos do termo "cena" - "cena cultural", como propõe Straw (2002 e 2015), "cena musical”, como usam Janotti e Sá (2015), entre outros. O que se observa, tanto do ponto de vista semântico quanto teórico, é o uso de termos como "drama", "encenação" e "cena" como recursos de enquadramento de fenômenos sociais e midiáticos, tentando operacionalizar uma narrativa com fins interpretativos.

Os enquadramentos cênicos dos fenômenos sociais são, portanto, articulados às próprias mudanças que ocorrem nas sociedades, afetando o estatuto teatral das ações, do que enquadramos como performático e do que julgamos ser do campo do estritamente teatral e/ou do social. A partir da ideia de mise-en-scène, Bernard Dort reitera que as molduras com que olhamos o social são sempre reordenadas a partir do que consideramos cênico, e que essas dimensões de teatralidade seriam variáveis temporais e espaciais. É sobre essa prescrição de Dort que desenvolvemos o principal argumento que sustenta a importância de retomar os usos da noção de teatralidade para dar conta de fenômenos midiáticos, uma vez que, na era da conexão e das vivências em redes sociais digitais, há um percurso que vai "da interioridade oculta para o comportamento visível", como atesta Sibilia (2008), e que é um dos principais fundamentos da inserção da ficção e da teatralidade no tecido social contemporâneo do qual a mídia faz parte. Ao mesmo tempo que insere a ficção nas tramas sociais, a noção de teatralidade modula a noção de Performance na medida em que o termo também está atrelado às "qualidades de um desempenho" ou às “atividades poiéticas centradas no gesto, no corpo em movimento, em necessária exposição ao olhar do outro, que lhe confere existência social".

A noção de teatralidade emerge, portanto, como aparato para compreender ações de sujeitos num mundo profundamente autoconsciente, reflexivo, obcecado por simulações e encenações em todos os âmbitos sociais. A teatralidade passa a ser uma lente através da qual enxergamos o Outro, em sua relação dramática com a vida e diante das inúmeras possibilidades de encenação em redes sociais digitais. Entende-se por teatralidade o espectro dramático que envolve a encenação, seja pela organização dos corpos colocados em cena, seja pela poética do espaço em que ocorre a ação, proporcionando a visualização de jogos de força que incidem sobre a verossimilhança e, portanto, sobre a experiência dos 
sujeitos. A teatralidade, como trabalhada neste artigo a partir do legado conceitual proposto por Féral, apresentar-se-ia em duas frentes: 1 . da ordem das materialidades, que seriam o modo como corpos e espaços se tornam visíveis e apresentáveis para sujeitos em contextos midiáticos, de que maneira essa aparição constitui uma episteme através da qual vemos e somos vistos, julgamos e somos julgados, apreendemos e somos apreendidos; 2 . da ordem das experiências, ou seja, como se dá a pragmática da teatralidade em contextos performáticos das redes sociais digitais, a partir dos engajamentos e da própria dinâmica presente nos meios, e seus diferentes modos de acionar afetos em ambientes profundamente autorreferentes.

O foco dos estudos sobre teatralidade é sempre a ação, entendendo esta como a disrupção da imobilidade, o gesto da atividade que vai desencadear um processo de comunicação por meio do qual se construirão diversas formas de engajamento. A ação é a disposição material de que partem hipóteses sobre a origem do gesto, sobre intenções e efeitos possíveis, fazendo com que se constitua, a partir da tomada de posição de um sujeito, disposta em ambiente midiático, um conjunto de variáveis que se edifica como motor e hipótese de investigação. As diferentes maneiras de encarar as ações teatralizadas têm-se espraiado do campo das Artes para as Ciências Sociais, agindo sobre as maneiras com que se entendem as ações humanas.

A teatralidade comporta também a noção de intangibilidade das ações. Ambiguidade e dúvida integram potências mobilizadoras de ações, não cabendo a tentativa da busca pela certeza, origem ou ontologia dos atos. As ações em redes sociais digitais seriam da ordem da camada performática que apresenta em si a sua teatralidade. Trata-se de instaurar um sistema valorativo sobre ações dos indivíduos em espaços públicos que se assemelhe àqueles consagrados pelas lógicas do espetáculo e das mídias. Este foco nas ações e nas superfícies dos atos nos direciona para a reflexão em torno do que se consagrou nas Teorias Discursivas como o estudo das cenas enunciativas. A seguir, propomos inferir sobre articulações em torno daquilo que as performances midiáticas nos "fazem enxergar": um conjunto turvo de possibilidades sobre a "busca pela verdade" das ações que nos impele a nos ater à teatralidade dos atos. 


\section{Teatralidade nas cenas enunciativas}

Debater a teatralidade significa adensar os estudos de Performance abrindo-se mais deliberadamente para o ato, a ação, o cênico: aquilo que se faz, como se faz, em que contexto (AMARAL, POLIVANOV e SOARES, 2018). Parte do que se chama de autoconsciência das ações significa reconhecer que tais ações são feitas "para alguém", para um Outro visível ou invisível, uma "audiência imaginada" ou "público intencionado", ao pensar as performances em sites de redes sociais. A tentativa é entender dinâmicas de construção de identidade e sociabilidade, que podem ser individuais ou coletivas, da ordem do cotidiano ou de eventos pontuais, sagradas ou profanas, efêmeras ou duradouras, envolvendo sujeitos comuns ou célebres, e mais ou menos mediadas por tecnologias da informação e comunicação (TICS). A noção de teatralidade auxiliaria metodologicamente na discussão sobre performance na medida em que colocaria em evidência de maneira mais enfática aspectos dramáticos das performances em ambientes midiáticos. Aposta-se que a teatralidade nos permitiria visualizar a dimensão dramatúrgica das performances, seus roteiros e experiências possíveis.

Recuperar o conceito de teatralidade e realizar movimentos teóricos sobre o debate midiático implica reconhecer a importância de uma nomenclatura já largamente utilizada nas teorias do discurso e linguagem: a cena. Embora a teatralidade seja propriedade do tecido social e, portanto, do cotidiano, pensar as ambiências das cenas, seus recortes, seus dentros e foras, aquilo que se coloca como enunciado nos convoca a reconhecer modos específicos de aparecer e convocar figuras de enunciação. A partir do amplo debate sobre as cenas enunciativas na Comunicação (FAUSTO NETO, 2007) e sobretudo suas possibilidades analíticas nos processos de midiatização, destacam-se cenas enunciativas como especificações nos espaços de enunciação, ou seja, ambientes particularizados de agenciamento dos sujeitos. Trata-se de configurações específicas do agenciamento enunciativo para "aquele que fala" e "aquele para quem se fala". Na cena enunciativa, "aquele que fala" ou "aquele para quem se fala" são agenciamentos enunciativos, lugares constituídos pelos dizeres que negociarão com as temporalidades inscritas nos atos: em que momento, sob que circunstância tais discursos emergem, abrindo margem para a constituição de quadros especulativos potentes de engajamento e adesão por aqueles que observam os enunciados. Assim, deter-se sobre as cenas realça necessariamente a consideração sobre o próprio modo de constituição dos cruzamentos entre espacialidades, temporalidades e teatralidade dos sujeitos. Essas 
reflexões estão próximas do conjunto de formulações sobre Performance nos estudos sobre oralidade, textualidade e poéticas da fala na obra de Paul Zumthor (1993, 1997, 2000).

As cenas enunciativas são importantes matrizes para a discussão da Performance em diálogo com os estudos de Linguagem (AUSTIN, 1990), sobretudo a partir da premissa de Austin e seu debate sobre o "performativo" 2 , ou seja, como as palavras e ações instauram estatutos sociais, reativam o cotidiano, criam liminares ${ }^{3}$ nas relações entre ações. O performativo, como pensando por Austin, é central no debate sobre teatralidade, na medida em que faz ressaltar o aspecto declaratório e temporal dos atos. A troca de "sim" num casamento, o corte da fita de uma cerimônia política, a declaração de guerra entre países são palavras que instauram ações e, portanto, provocam agência sobre o vivido. Num contexto de redes sociais digitais, a mudança de estatuto afetivo, a concordância com linhagens políticas, a crítica a produtos culturais, entre outras disposições performativas, instauram estatutos relacionais entre sujeitos: acionam aproximações, afastamentos, rompimento de laços de amizade e de comunhão. O estatuto performativo das ações em rede sociais digitais criaria espaços liminares no tecido social, entendendo a liminaridade como esfera limítrofe nos ritos de passagem do vivido e de suas relações com outras ambiências do social e também com o reordenamento das mobilizações em torno dos sujeitos que protagonizam o performativo.

Reconhecer a teatralidade no debate sobre cenas enunciativas pressupõe enfrentar as diferentes espacialidades e ambiências de onde emergem essas ações e o modo como o especular integra o próprio espaço. No ambiente midiático, a noção de intenção (que é tão cara à ideia de teatralidade) aparece como uma perspectiva que nos coloca diante do apagamento da transparência das ações. Ressaltam-se, portanto, as conexões entre o que se evidencia e um invisível-intencional que está presente a partir da aparição. A teatralidade pressupõe reconhecer uma certa "intenção de teatro", como sugere Féral, em que o evento, o especular e o espetacular parecem atados triangulando maneiras de ver e ser visto. A autora destaca movimentos que envolvem esta triangulação: a ficção que emerge do próprio cotidiano, a

20 performativo emerge em enunciados que, quando proferidos na primeira pessoa, na forma afirmativa e na voz ativa, "realizam uma ação" (daí o termo "performativo": o verbo inglês "to perform" significa realizar). "Declaro aberta a sessão"; "Ordeno que você saia"; "Eu te perdoo" são enunciados que, no exato momento em que são proferidos, realizam a ação denotada. Nesse sentido, dizer algo é fazer algo. Propõe-se pensar o estatuto performativo como instância de teatralidade nas performances midiáticas em redes sociais digitais: inícios de relacionamento, fins de acordos, rompimentos de laços, entre outros.

3 A ideia de liminaridade foi amplamente debatida, sobretudo na Antropologia, como correspondendo a um momento de margem dos ritos de passagem: fase ritual na qual os sujeitos se apresentam indeterminados, em uma espécie de processo transitório de "morte" social, para, em seguida, "renascerem" e reintegrarem-se à estrutura social. Para mais detalhes: http://ea.fflch.usp.br/conceito/liminaridade-e-communitas-victor-turner. 


\section{ALCEU}

ISSN: $2175-7402$

semiotização dos espaços e o deslocamento de signos que fazem emergir simulacros. A teatralidade estaria, portanto, numa intenção de teatro cujo pacto precisaria ser reiterado e constantemente atualizado. Não seria inerente às cenas enunciativas, mas sim operacionalizada a partir das organizações discursivas e dos pactos previstos. A teatralidade, assim, não estaria relacionada à natureza do objeto que investe (sujeito, espaço, evento) e tampouco estritamente ao simulacro, ilusão, aparência, ficção. Mais que uma propriedade, trata-se de um processo, produzido a partir de enquadramentos que criam um outro espaço, tornado espaço do Outro que dá lugar à alteridade dos sujeitos e à emergência da ficção.

Quero nominar mais detidamente aquilo que chamo de ambiente midiático e me ater ao espaço em específico das redes sociais digitais e à convocação de um "bios cênico" (BARBA, 1994) em suas implicações de poder e vigilância sobre sujeitos. Na vivência em redes sociais digitais, o simples exercício de olhar a ação do Outro inscreve a teatralidade, colocando a gestualidade desse Outro no espaço do especular. A clivagem no espaço ${ }^{4}$ instaura um fora e um dentro da teatralidade, não sendo apenas a emergência de uma fratura no espaço, uma clivagem no real que convoca um espaço de alteridade, mas a própria constituição desse espaço por meio do olhar do espectador, olhar este que produz alterações nas relações qualitativas: "o outro torna-se ator seja porque mostra que representa seja porque o olhar do espectador transforma-o em ator - a despeito dele - e o inscreve na teatralidade" (FÉRAL, p. 87). A teatralidade nas redes sociais digitais consistiria tanto em situar sujeitos nesse outro espaço de clivagem que é possível graças ao efeito do enquadramento através do qual inscrevo o que olho quanto em transformar um evento em signo.

Os constantes acionamentos nas redes sociais digitais envolvendo convocatórias previstas nos algoritmos podem ser pensados nas maneiras como somos interpelados rotineiramente a atuar em escala pública e global ou naquilo que se chamou, de maneira quase instintiva, por autores da gênese do conceito de teatralidade, de "vontade de teatro": gosto pelo lúdico, prazer de criação de ilusão, projeção de simulacros, fonte inesgotável de simulacros de si potencializados numa vida em rede que nos convoca cotidianamente a expor fragmentos do cotidiano na tentativa de formação de redes de compatibilidade e afeto, mas que também resulta em sistemas de disputa, exclusão e disrupção.

4 É possível pensar diferentes modos de se referir a esse espaço ao longo das teorias que pensaram a Performance, como espaço transicional (Winnicott), espaço liminar (Turner), espaço de enquadramento (Goffman). 


\section{Protocolos para Estudo das Teatralidades das Performances Midiáticas}

É na direção de adensar o debate sobre Performance no campo da Comunicação que se propõe o estudo sobre a teatralidade das performances midiáticas, a partir de dois movimentos interpretativos oriundos de indicativos metodológicos em que se constituirão bases sobre as quais se visualizarão as dimensões cênicas das performances analisáveis.

1. Estudo das dramaturgias: Quando me refiro à dramaturgia, estou propondo o mesmo movimento epistemológico que Victor Turner realizou a partir de sua noção de drama social, ou seja, o desenvolvimento de modelos de análise de conflitos no social a partir da metáfora do drama teatral. 0 conceito de drama social foi formulado pelo autor em Schism and Continuity in an African Society: A Study of Ndembu Village Life, em 1957, e ressalto a dimensão sociológica presente na proposição de Turner na medida em que é possível apreender como o conflito é um mecanismo produtor da dinâmica e da unidade da vida social. No plano descritivo, entendem-se, por conflito, as querelas e os desentendimentos que, de tempos em tempos, eclodem das mais diversas maneiras no cotidiano da região estudada pelo autor. (CAVALCANTI, 2013)

Geradas pelo rompimento de alguma conduta esperada entre os atores sociais, essas brigas se desdobravam, como descobriu Turner, em um processo que obedecia a uma sequência padronizada de ações englobadas pelas quatro conhecidas fases do drama social: 1. crise: o reconhecimento de uma crise que irrompe no cotidiano tornando manifestas tensões latentes inerentes às relações e interações sociais. 2. ampliação da crise: os sujeitos/atores atingidos atuam e acionam suas redes, relações de vizinhança e amizade; a crise se amplia gradualmente, atingindo novas esferas e envolvendo cada vez mais atores. 3. regeneração: alguns dos sujeitos/atores envolvidos mobilizam-se em prol de soluções e esforços de conciliação que implicam sempre a realização de ações rituais e amplos rituais coletivos. 4. rearranjo ou cisão: se bem-sucedidos, os esforços da fase anterior implicam um rearranjo e redefinições de posições e relações, e, se malsucedidos, configuram o rompimento do grupo, traduzido na sua cisão, que segue as clivagens de parentesco, e na criação de uma nova organização.

Destaco que os atores sociais dos dramas analisados por Victor Turner logo se convertem em personagens vívidos, cheios de traços peculiares e características, qualidades e defeitos. A vivência dentro da estrutura de um drama social ressalta características dramatúrgicas nesses sujeitos. A experiência vivida 
por eles no desenrolar do drama é subjetivada, produz reflexividade e pode modificar o próprio sujeito e seu grupo, acionando autoconsciência e, portanto, controle sobre ações e premissas.

As dimensões trágicas, cômicas, aterrorizantes das performances nas mídias colocam em cena dramas sociais que são acionados por atores sociais em contextos de alta visibilidade. A partir de seu texto Do ritual ao teatro, Turner propõe a noção de drama social como contingências dramáticas que acionam inícios, crises e desfechos de ações cotidianas que se materializam em formas de debater como as sociedades apreendem seus dramas e quais memórias fazem parte dessas ações.

Para Turner, as ações públicas observáveis no social formam estruturas temporais e espaciais sobre as quais se pressupõe enquadrar uma perspectiva dramática. Em muitos casos, pesa sobre o autor a crítica de evocar pressupostos estruturalistas na interpretação de fenômenos sociais e no tratamento estático e prescritivo das molduras dramáticas que resultam dessas ações. Interessa-nos neste movimento pensar menos em estruturas, e mais em enquadramentos para ações públicas de sujeitos em rede num contexto de alta visibilidade, na tentativa de reconhecer que somos rotineiramente convocados a refletir sobre postagens em redes sociais, seus intuitos, motivações, acionamentos e desfechos.

Nesse sentido, parece-nos central postular a existência de enquadramentos dramáticos que partem de enunciados e interrogam quais são as relações entre o que se diz e por que se diz o que se diz. Pensar sobre esses enquadramentos significa recuar no campo dos discursos, observar de fora da cena, compondo uma clivagem a partir dos elementos que são tanto destacados pelo enunciado quanto reconhecíveis a partir do ponto de vista de quem observa. O movimento de recuar diante de um episódio impele reconhecer a tessitura da intriga e da memória dos atos, como tais narrativas se fazem presentes e em que contexto. Essa "montagem da cena" a partir dos enunciados em rede integra aquilo que chamamos de teatralidade.

A teatralidade nas performances midiáticas aponta para o reconhecimento de dramas sociais e de agenciamentos em fenômenos midiáticos tais como irrupções de crises entre políticos, revelações entre celebridades, rompimentos entre sujeitos nas mais diversas ordens. A nossa proposta é esboçar o que chamamos de abordagem dramatúrgica para os conflitos performáticos em rede: que natureza de drama tais ações convocam? A partir dos conceitos propostos por Turner, tentaremos enquadrá-los na abordagem para performances midiáticas. A ideia de ruptura soa fundamental para dar conta das quebras 
de pactos nas relações sociais formais. Desde a polarização política pós-2013 que se vive cotidianamente o anúncio público de dissidências acarretadas pelo fato de "tornar público" algo: o apreço por um político; por uma situação histórica; pelo engajamento em torno de uma causa. Entende-se, a partir das indicações de Turner, que rupturas são estopins simbólicos de confrontos ou embates, violando algum pacto prévio e indicando que ações podem traduzir gestos individuais ou apontar para o coletivo. As rupturas esgarçam as teias de relações já existentes a partir de mal-entendidos, controvérsias, "tretas" ou ruídos que podem ser propositalmente produzidos.

Rupturas acionam, portanto, crises que tendem a se alargar e envolver outros indivíduos, situações, instituições, podendo tornar-se coextensivas de um quadro mais amplo que de relações conflitantes. Turner utiliza o termo "escalada da crise" para tratar do crescimento exponencial da ruptura e acionar a formação da intriga. É quando se instaura a crise que, de fato, a teatralidade se constrói no social: quais as posições dramáticas dos atores sociais? Heróis, vilões, articuladores, inocentes? O que emerge do roteiro? O humor, o drama, o terror? A crise convoca a triangulação das ações para o ficcional corrente dentro do social, apelando para inflexões em torno do perigo, do suspense, quando atores "vestem máscaras" e se posicionam na cena construída no próprio tecido social. As crises constroem zonas liminares nas performances midiáticas que podemos pensar como balizas limítrofes sobre as quais se edificam as diegeses ficcionais, espaço de criação especulativo e indicativo das zonas tensivas das ações.

As ações corretivas, por sua vez, limitam a difusão da crise, funcionam como mecanismos de ajustes e regeneração, formais ou informais, institucionalizados ou não, operacionalizados para que se contenha a perturbação. Tipologias de ações corretivas bem como sua complexidade variam de acordo com interesses institucionais que, inevitavelmente, emergem como aparato de aconselhamento, mediação, arbitragem, legitimando formas de resolução em rituais públicos. O exame das ações corretivas nos dramas sociais convoca perspectivas autoconscientes, tornando mais latentes os indicativos de atenuação do espraiamento das crises. Dramas sociais também promovem reintegrações, que são as organizações em torno do perturbado, na legitimação social do cisma, na acomodação dos pontos de vista e nas fissões ou reconciliações. Turner alerta que esses procedimentos formam estruturas temporais e atemporais que se sobrepõem, formando núcleos de coesão e de interesses a partir da busca por fundamentos das ações. 
Do ponto do vista metodológico, investidas na articulação entre performance e drama social formam um importante legado na tradição de estudos antropológicos e teatrais. Destaco uma aproximação que leva em consideração a dimensão midiática dos dramas sociais. Diana Taylor (2013) analisa as inúmeras manifestações do que chama de "arquivo da tristeza", quando da ocasião da morte da princesa Diana - ocorrida em 1997 -, a partir dos enlaces entre o enredo trágico e a teatralidade das encenações nas mídias. O método do drama social de Turner é utilizado pela autora na tentativa de demarcar as etapas e intensificações dos artefatos cênicos das ações, funcionando como uma ferramenta de demarcação de ações e de suas teatralidades. Para Taylor, a morte de Diana se intensifica em seu caráter global na medida em que negocia com um conjunto de atos que colocam em evidência a forma como sociedades apresentam seus dramas. A partir das rupturas estruturais (o divórcio de Charles e o afastamento da Família Real); da crise do drama de sua morte trágica (colocando em evidência a imagem da "amante trágica"); das ações reparadoras através da performance de fãs em seu funeral, dos atos e da forma cultural de celebrar a morte; e, por fim, da maneira com que a princesa Diana é reintegrada ao social através do midiático, ou seja, a fantasmagoria de Lady Di projetada em filmes, séries e atrativos da cultura pop, Taylor concebe indicativos metodológicos substanciais para o desenvolvimento de análises que levem em consideração a dramaturgia das performances nas redes sociais digitais - aparto central para a proposta teórico-metodológica sintetizada neste artigo.

2. Estudo dos roteiros performáticos: Toda encenação comporta um roteiro, uma "configuração paradigmática que conta com participantes supostamente ao vivo, estruturados, ao redor de um enredo esquemático, com um fim pretendido (apesar de adaptável)" (TAYLOR, 2013, p. 41). A proposição é estruturar um modo de observar as performances midiáticas em redes sociais como roteiros de encontros e desencontros, uma narrativa que se apresenta encenada: um grupo de sujeitos e uma plateia, num cenário enunciativo, um contexto cultural. Queremos propor um método de análise dos roteiros como uma forma de entender as performances como o sumário, esboço, rascunho que dá informação sobre as cenas, situações. Barthes (2003) já havia postulado que pensar através da premissa dos roteiros significa reconhecer a existência de algo prévio, já trabalhado antes, "arcabouço portátil" que carrega o peso dos acúmulos e das repetições. Pensar através da ideia de roteiro nos fornece subsídios para reconhecer tanto o implícito das encenações (e tentar resgatar esses implícitos por meio de dados primários ou secundários) quanto aquilo que se coloca explícito, os clichês das encenações, sobretudo através dos estereótipos. 
Chamamos a atenção para o fato de que investigar performances midiáticas demanda não apenas um olhar atento ao campo do simbólico, do que atos performáticos querem propor enquanto "produção de sentido", mas também para algo da ordem não hermenêutica, que envolve as materialidades dos corpos e objetos que se afetam e produzem presença - para evocar o termo debatido por Gumbrecht (2010). Ainda que tal presença possa ser "arquivada" midiaticamente, desenha-se o entendimento de que se trata de um processo sempre inacabado, em construção, ainda que certos atos performáticos e seus registros - como shows de música e apresentações teatrais - possam trazer uma ideia de término ou conclusão. Dentro da perspectiva de Taylor, eles não se encerram em si mesmos, são sempre lidos e interpretados em diferentes contextos históricos, à luz dos enquadramentos teóricos e empíricos de cada época, causando afetações, reverberações e reelaborações mesmo após seu suposto fim.

O que Taylor está reivindicando é parte do que Derrida (2001) também já mencionou: arquivos são sempre vivos e prontos para serem lidos a partir da perspectiva do presente, evocando uma dimensão processual da performance que apenas "parece" estática em sua relação com a História. Entretanto, é exatamente o fincar histórico que situa os arquivos menos como um reflexo do passado, e mais como o que foi possível ser feito naquele contexto, em que implicações existiam para que uma encenação fosse produzida do jeito que foi. Observar imagens arquivais a partir da perspectiva dos roteiros performáticos possíveis é, de acordo com Taylor, um exercício metafórico em torno também das performances e ações cotidianas: como postula Goffman, sempre reelaboradas e reconstruídas.

O grande roteiro na história das Américas, lembra Taylor, é o do Descobrimento: personagens se delineiam nestas narrativas históricas (o descobridor, os nativos, entre outros). Tais narrativas históricas assombram o presente quando reencenadas, apresentadas como inéditas, podendo "assustar" nossa compreensão diante de um outro final possível. Metodologicamente, os roteiros nos impelem a observar mais atentamente os gestos, as atitudes, os tons - simultaneamente montagem e ação, ativação e moldura de dramas. A montagem exibe elementos como encontro, conflito, resolução, desenlace. Desenha-se uma zona de fricção entre atores sociais e personagens, o aparecimento de agenciamentos culturais de inúmeras maneiras. Sobre o método do roteiro como análise de performances, Taylor sugere a observação analítica de, ao menos, três quadros performáticos constituintes da dramaticidade:

1. o local físico em que se dá a apresentação, uma "cena", que denota intencionalidade em termos artísticos e políticos, sinaliza estratégias conscientes de exibição. A autora sugere a noção de palco 
material tanto quanto de ambientes codificados (países, cidades, ruas, etc). "Lugares nos permitem pensar sobre possibilidades e limites de ação. Porém, a ação também define o lugar" (TAYLOR, 2013, p. 62).

2. a corporalidade dos atores sociais ou a construção social dos corpos em contextos definidos, os detalhes visuais, as peculiaridades da aparência, dos gestos e das falas. As zonas tensivas entre "enredo" e "personagem" e o que se apresenta como solução expressiva.

3. a montagem das ações como estruturas que seguem fórmulas, predispõem resultados e também abrem margem para se pensar inversões, paródias, mudanças. "O roteiro força-nos a nos situar em relação a ele; como participantes, testemunhas ou espectadores" (TAYLOR, 2013, p. 62). A montagem das ações comumente invoca situações passadas, que fazem parte de um acervo de memória e de sua potência significante.

A partir dos indicativos de Taylor, propomos pensar a performance a partir dos atravessamentos midiáticos: suas entradas, saídas e as permanências dos corpos na esfera das mídias. Como tais corpos se colocam em cena, o que teatralizam. A abordagem da performance precisa reconhecer a própria dinâmica midiática como uma camada performática. As mídias formam, em si, agenciamentos performáticos que indicam modos particulares de agir, olhar, interagir, valorar.

\section{Considerações finais}

O artigo propõe apresentar protocolos teórico-metodológicos para o estudo das ações de sujeitos em redes sociais digitais tomando tais ações como quadros performáticos que se organizam em roteiros performáticos, instauram dramas sociais e propõem diferentes formas de engajamento e de experiência em rede. Trata-se da revisão de um conjunto de autores fundamentais dentro do campo da Comunicação, da Antropologia, da Sociologia e das Artes Cênicas para tentar compreender a pragmática dos embates performáticos em rede que se configuram na principal sustentação do “bios midiático" (SODRÉ, 2013, p. 1).

O bios midiático seria da ordem da clivagem midiática aplicada à vida cotidiana, à existência histórica do indivíduo num ecossistema de mídias. Nas condições civilizatórias contemporâneas, de urbanização intensa, relações mercadológicas da vida, trata-se de uma inflexão exacerbada do imaginário e das tramas narrativas do ficcional no cotidiano midiatizado. Os efeitos de fascínio em torno do intenso 


\section{ALCEU}

ISSN: $2175-7402$

processo de celebrização dos sujeitos resultam em formas de viver midiaticamente que privilegiam a estesia na presença. "O fenômeno estético toma-se insumo para a estimulação da vida, doravante dirigida para a indústria e o mercado. É, portanto, mais aisthesis do que ethos - embora se possa falar de um ethos da estética, ou seja, de uma inteligibilidade do sensível capaz de levar a uma ética ou uma arquitetura social de valores" (SODRÉ, 2013, p. 2).

Desdobram-se os desafios sobre a compreensão dos atos de sujeitos em rede na contemporaneidade. As reflexões sobre Performance acionam o debate sobre a intangibilidade da verdade sobre as ações. Emergem quadros complexos de interpretação de fenômenos em que a teatralidade passa a ser um valor para a vivência em rede. Trata-se da premissa em torno do domínio da dramaturgia, das resultantes possíveis dentro de um determinado roteiro. A tessitura da intriga da vida midiática requer engajamentos de diferentes ordens no conjunto de práticas observáveis em rede.

Thiago Soares

ORCID: https://orcid.org/0000-0002-1305-4273 Universidade Federal de Pernambuco, Programa de Pós-Graduação em Comunicação, Recife (PE), Brasil Doutor em Comunicação e Cultura Contemporâneas pela UFBA E-mail: thiago.soares@pq.cnpq.br

Recebido em: 18 de fevereiro de 2020.

Aprovado em: 23 de junho de 2020.

\section{Referências}

AMARAL, Adriana. Manifestações da performatização do gosto nos sites de redes sociais: uma proposta pelo olhar da cultura pop. Revista Eco-Pós. v.17, n.3, 2014. p. 1-12.

; POLIVANOV, Beatriz; SOARES, Thiago. Disputas sobre performance nos estudos de Comunicação: desafios teóricos, derivas metodológicas. Revista Intercom - RBCC. São Paulo, v.41, n.1, jan./abr. 2018. p.63-79. 


\section{ALCEU}

ISSN: $2175-7402$

AUSTIN, J.L. Quando Dizer é Fazer - Palavras e Ação. Porto Alegre: Artes Médicas, 1990.

BARBA, Eugênio. A canoa de papel: tratado de antropologia teatral. São Paulo: Hucitec, 1994.

BARTHES, Roland. Mitologias. São Paulo: Difel, 2003.

BRUNO, Fernanda. Monitoramento, classificação e controle nos dispositivos de vigilância digital. Revista Famecos. v.15, n. 36. Porto Alegre, 2008. p. 10-16.

BUTLER, Judith. Problemas de Gênero: Feminismo e Subversão de Identidade. Rio de Janeiro: Civilização Brasileira, 2015.

CAVALCANTI, Maria Laura Viveiros de Castro. Drama, ritual e performance em Victor Turner. Revista Sociologia \& Antropologia. v.3. n.6. Rio de Janeiro, novembro, 2013. p. 411-440.

DERRIDA, Jacques. Mal de Arquivo: Uma Impressão Freudiana. Rio de Janeiro: Relume Dumará, 2001.

DORT, Bernard. O Teatro e Sua Realidade. São Paulo: Perspectiva, 1977.

FAUSTO NETO, Antônio. Enunciação, auto-referencialidade e incompletude. Revista Famecos. v.13, n. 34. Porto Alegre, 2007. p. 78-85.

FÉRAL, Josette. Além dos Limites: Teoria e Prática do Teatro. São Paulo, Perspectiva: 2015.

GOFFMAN, Erving. The presentation of self in everyday life. Harmondsworth: Penguin, 1969.

GUMBRECHT, Hans Ulrich. Produção de presença - o que o sentido não consegue transmitir. Rio de Janeiro: Contraponto e PUC-Rio, 2010.

HENNION, Antoine. Pragmatics of taste. In: JACOBS, M., HANRAHAN, N. The Blackwell Companion to the Sociology of Culture, Blackwell, pp.131-144, 2005.

Music Lovers. Taste as performance. Theory, Culture \& Society, v. 18, n. 5, Dec. 2007.

JANOTTI, Jeder e SÁ, Simone Pereira de. Cenas Musicais. Rio de Janeiro: Anadarco, 2015. p.

MEAD, George. Mind, self and society. Chicago: University of Chicago Press, 1934.

SIBILIA, Paula. O show do eu: a intimidade como espetáculo. Rio de Janeiro: Nova Fronteira, 2008.

. O artista como Performer: Dilemas do Eu Espetacular nas Artes Contemporâneas. Performance Presente Futuro. Rio de Janeiro: Contracapa, 2010.

. Autenticidade e performance: a construção de si como personagem visível. Fronteiras - Estudos Midiáticos. v.17, n.3, 2015.

SÁ, Simone Pereira de. Somos Todos Fãs e Haters: Cultura Pop, Afetos e Performance de Gosto nos Sites de Redes Sociais. Revista Eco-Pós. v.19, n.3, 2016. 
SÁ, Simone Pereira de e POLIVANOV, Beatriz. Auto-Reflexividade, Coerência Expressiva e Performance como Categorias para Análise dos Sites de Redes Sociais. Revista Contemporanea - Comunicação e Cultura. v.10, n.03, set-dez 2012. p. 574-596.

STRAW. Will. Scenes and Sensibilities. Public. n.22, v.23. 2002. p. 245-257.

. Cenas Culturais e as Consequências Imprevistas das Políticas Públicas. In: JANOTTI, Jeder e SÁ, Simone Pereira de. Cenas Musicais. Rio de Janeiro: Anadarco, 2015. p. 13-28.

SODRÉ, Muniz. Bios Midiático. Dispositiva. Belo Horizonte, v.2, n.1, maio/outubro de 2013. p. 108-110.

TAYLOR, Diana. $\mathbf{O}$ arquivo e o repertório: performance e memória cultural nas Américas. Belo Horizonte: Editora da UFMG, 2013.

TURNER, Victor. Schism and continuity in an African society. Manchester: Manchester University Press, 1996.

From Ritual to Theater: The Human Seriousness of Play. New York, Performing Arts Journal Publications, v.22, n.1. p-13-27. Janeiro de 1982.

ZUMTHOR, Paul. A letra e a voz. São Paulo: Companhia das Letras, 1993.

. Tradição e esquecimento. São Paulo: Hucitec, 1997.

\section{Resumo}

Debater a natureza das performances midiáticas requer apreender sua teatralidade: a dramaturgia, o roteiro, os enlaces ficcionais que mantêm potentes as tramas envolvendo sujeitos. Num contexto profundamente autorreferente, em que posicionamentos e encenações em redes sociais digitais acionam conflitantes pontos de vista sobre indivíduos, é preciso questionar: quais as variáveis em torno da adesão a ações performáticas em contextos de rede sociais digitais? $A$ análise de controvérsias envolvendo sujeitos em contextos de alta visibilidade modulam diferentes formas de teatralizar conflitos, acionando uma pragmática da ação em rede e seus lugares de atuação em diferentes quadros performáticos.

Palavras-chave: Performance. Teatralidade. Drama social. Redes sociais digitais. 


\section{Abstract}

Debating the nature of the media performances requires apprehending its theatricality: the drama, the script, the fictional links that keep potent the plots involving subjects. In a deeply selfreferential context, in which positions and scenarios in digital social networks trigger conflicting points of view about individuals, it is necessary to question: what are the variables around the adhesion to performance actions in digital social network contexts? The analysis of controversies involving subjects in high visibility contexts modulate different ways of theater conflict, triggering a pragmatic of network action and their places of performance in different performative frames.

Keywords: Performance. Theatricality. Social drama. Digital social networks.

\section{Resumen}

Debatir la naturaleza de las performances en los medios requiere comprender su teatralidad: la dramaturgia, el guión, los vínculos ficticios que mantienen potentes las tramas que involucran temas. En un contexto profundamente autorreferencial, en el que las posiciones y la puesta en escena en las redes sociales digitales desencadenan puntos de vista conflictivos sobre los individuos, es necesario preguntarse: ¿cuáles son las variables en torno a la adhesión a las acciones de performance en contextos de redes sociales digitales? El análisis de controversias que involucran a sujetos en contextos de alta visibilidad modulan diferentes formas de teatralizar conflictos, desencadenando una acción pragmática de la red y sus lugares de actuación en diferentes marcos de actuación.

Palabras clave: Performance. Teatralidad. Drama social. Redes sociales digitales.

Este artigo é publicado em acesso aberto (Open Access) sob a licença Creative Commons Attribution Non-Commercial (CC-BY-NC 4.0), que permite que outros remixem, adaptem e criem a partir do seu trabalho para fins não comerciais, e embora os novos trabalhos tenham de lhe atribuir o devido crédito e não possam ser usados para fins comerciais, os usuários não têm de licenciar esses trabalhos derivados sob os mesmos termos. 